\title{
Women in conflict and indigenous conflict resolution among the Issa and Gurgura clans of Somali in Eastern Ethiopia
}

\author{
Bamlaku Tadesse, Yeneneh Tesfaye and Fekadu Beyene ${ }^{\star}$
}

\begin{abstract}
This article tries to show the impacts of conflict on women, the role of women in conflict and indigenous conflict resolution, and the participation of women in social institutions and ceremonies among the Issa and Gurgura clans of the Somali ethnic group. It explores the system of conflict resolution in these clans, and women's representation in the system. The primary role of women in the formation of social capital through marriage and blood relations between different clans or ethnic groups is assessed. The paper focuses on some of the important elements of the socio-cultural settings of the study community that are in one way or another related to conflict and indigenous conflict resolution mechanisms. It also examines the positive aspects of marriage practices in the formation of social capital which strengthens friendship and unity instead of enmity.
\end{abstract}

* Mr Bamlaku Tadesse has an M.A. in Social Anthropology and is Head of the Department of Gender and Development at the Institute of Pastoral and Agro-Pastoral Studies, Haramaya University, Dire-Dawa, Ethiopia.

Mr Yeneneh Tesfaye also has an M.A. in Social Anthropology and works in the Department of Rural Development and Agricultural Extension at the College of Agriculture and Environmental Sciences, Haramaya University.

Dr Fekadu Beyene is a Resource Economist and Assistant Professor in the Department of Rural Development and Agricultural Extension, and Director of the Institute of Pastoral and Agro-Pastoral Studies at Haramaya University.

(Note: The names and details of two of the co-authors do not appear in the printed copies of this issue, since due to an unfortunate misunderstanding this information arrived only after the printing had already been completed.) 


\section{Bamlaku Tadesse}

\section{Background}

Erer district is located in the Shinle zone of the Somali region which is about $60 \mathrm{~km}$ from Dire-Dawa and located to the north-west of the capital Jijiga. The area is characterised by arid and semi-arid environment. The district has 23 kebeles (peasant associations), of which about 13 are predominantly inhabited by the Gurgura clan and the rest by the Issa clan. Based on their livelihood strategies, the population could be identified as pastoralist, agropastoralist and urban dweller communities. The population in the study area is characterised by homogeneous communities in terms of cultural (i.e. religion and language) as well as social practices. The Issa are mainly pastoralist communities living in the arid and semi-arid areas of Ethiopia and Djibouti, and the Gurguras are mostly agro-pastoralist communities. The Gurguras are a mixture of the Somali (Issa) and Oromo (Nolle) ethnic groups.

Furthermore, the Gurgura, Issa and Hawiya clans are Somali ethnic groups speaking the Somali language and residing in the Somali regional state while the Ittu and Nolle clans are Oromo ethnics speaking the language of Afan Oromo and residing in the Oromia regional state. Afar is an ethnic group speaking the Afar language and residing in the arid and semi-arid climates of Afar regional state. All of the above mentioned clans and ethnic groups are linguistically categorised under the Cushitic language family of Ethiopia.

Local conflicts in pastoral areas have been a common phenomenon since time immemorial. They are often characterised by competition over grazing land and water resources and by livestock raiding and looting. Such kinds of conflicts were further intensified with the declining nature of the pastoral mode of life and the type of state responses (Kandagor 2005). Resource scarcity is leading to unsustainable pressure on vital resources such as pasture and water, and thus to increasing levels of violent competition and tension between local communities. In the case of Erer, conflicts happen due to the scarcity of available natural resources (water points, farming and pasture lands). Conflicts could be intra- or inter-clan, inter-ethnic, or interpersonal (due to boundary conflicts on farm lands and problems of access 


\section{Women in conflict and indigenous conflict resolution in Eastern Ethiopia}

to irrigation water). The inter- and intra-clan conflicts between and among the Issa and the Gurgura clans are due to competition over scarce natural resources like water and pasture land, as well as to cattle raiding.

Besides the conflicts with a socio-economic dimension, there are also administrative boundary conflicts which have political and ethnic dimensions. Such kinds of conflicts include the ethnic conflicts between groups who consider each other as traditional enemies: the Issa clan of Somali and Afar ethnic groups, the Ittu clan of Oromo and the Hawiya clan of Somali ethnic groups, the Issa clan of Somali and the Nolle clan of Oromo ethnic groups and the Gurgura clan of Somali and their neighbouring Nolle clan of Oromo ethnic groups. According to the field work investigation, such kinds of conflicts were common around the Meiso, Bordede, Afdem and Bike areas which are located in the north-western part of the Somali regional state bordering on the Oromia and Afar regional states. These areas, situated at the confluence of the three regional states, are the most conflict-prone areas of eastern Ethiopia in which the different ethnic groups and clans are living together but in a hostile manner. The conflict in the area intensified after the decision was reached in 2003 by the federal and regional governments of Somali and Oromia regional states to conduct a referendum towards resolving their long-standing border disputes. After this decision, conflict and confrontation around the referendum issue in order to influence the referendum results were common. This kind of conflict between the Somali and Oromia regional states is also becoming common in the study area after the referendum took place in Erer district ${ }^{1}$ in 2003 (Interview with Fetulle community elders, Erer district, 30 0ctober 2008).

The administrative boundary conflicts between regional states, which emerged with the introduction of the new federal arrangement, seem to have contributed to the rearrangement of previous local conflicts. Many of these conflicts reflect the already existing local resource competition over land resources. But the new constitutional order, particularly the disputed

1 Among the 23 kebeles of Erer district, the referendum took place in all 13 the kebeles in which the Gurguras lived. One of them, Serkama, now belongs to the Oromia regional state as a result of the referendum. 


\section{Bamlaku Tadesse}

boundary between the regional states, has offered new energy by offering new legitimacy to pre-existing local conflicts and competition, whilst infusing both with an ethnic dimension. However, both the federal government of Ethiopia and the regional states have been trying to resolve these conflicts, especially those between Somali and Oromia regional state boundary areas. It has been over a decade since ethno-regional boundary disputes became persistent along the boundary between the states of Somali and Oromia, since their formation in 1992 (Ahmed 2005).

Women have minimal direct participation in indigenous institutions ${ }^{2}$ of conflict resolution for a variety of reasons. Because women lack formal political platforms, they often draw credibility and strength from a wider social base and promote their agenda at the grassroots level (Manchanda 1999). The absence or minority presence of women in discussions about conflict resolution or the implementation of outcomes of such discussions brings about unfortunate results. Peace agreements in which their concerns and priorities have not been well addressed may be unjust and ineffective, and may lack long-term viability (Bates 2000; Burton and Dukes 1990). The invisibility of women in socio-economic and political affairs, the widespread acceptance of religious and cultural justifications for the unequal treatment of women, and the lack of regional and national significance attached to women's lives explain the marginalisation of women in all affairs. Women experience conflicts differently and in ways that men do not experience at all. Their experience must be considered in all conflict-resolving efforts of negotiations and discussions. Otherwise the peace process will only be obtained for half the population (Rosenblad 2007; Pastoralist Forum Ethiopia 2006; Somali Region Pastoral and Agro-pastoral Research Institute 2007). In Erer district, they are marginalised in several respects, including indigenous conflict resolution although they account for the majority of the population.

2 Indigenous institutions in this study are those structures that matter most in the social realm, particularly with regard to conflict resolution mechanisms (like community elders, clan and religious leaders). They are established by the communities who have common understandings of their norms, values, rules, sanctions and principles (Hodgson 2006). 


\section{Women in conflict and indigenous conflict resolution in Eastern Ethiopia}

\section{Materials and methods}

An interpreter with a wide range of kinship and social networks was recruited. In the collection of research material, several methods were employed. The main methods used were informal and semi-structured interviews, focus group discussions and case studies. Initiatives were made to meet as many residents as possible in informal discussions on some general issues relating to their modes of living and their socio-economic conditions. In due course, different categories of the Issa and Gurgura communities (old, young, men and women) were asked about their perceptions of the institutions for conflict resolution, their views about the level of women's participation and those factors that discourage them, the decisions made and their effectiveness in restoring peace and order in the area. These interviews helped me to identify key informants for the semi-structured interviews.

Key informants were selected purposively on the basis of their age and knowledge/awareness about their culture, society and environment. The semi-structured interviews were intended to access information about Gurgura and Issa socio-cultural practices (marriage, kinship relationships, descent or lineage ties, etc) that contribute to the low level of women's participation in conflict resolution. In-depth interviews with key informants were conducted in order to have their description of events. Case studies were also conducted to document the nature of dispute cases handled by institutions for dispute settlement at different levels.

Besides, secondary sources were used to obtain background information on the socio-economic conditions of the Issa and Gurgura clans of Somali. Some theoretical background information related to conflict resolution and participation of women was also gathered from secondary sources. The qualitative data were analysed based on the theoretical and methodological principles of interpretation. A descriptive case study analysis technique was employed for the ethnographic description, interpretation and analysis of qualitative data. 


\section{Bamlaku Tadesse}

\section{Results and discussion}

\subsection{The Impacts of Conflict on Women}

Women and men have different access to resources, power and decision making before, during and after conflicts. The experience of women and of men in conflict situations is significantly different. While entire communities suffer the consequences of conflict, women and girls are particularly affected because of their status in society and their sex. Women are thus caught in a vicious paradox: while they are the main civilian victims of conflicts, they are often powerless to defend themselves, they are excluded from the negotiations during the resolution process, and they are confined to a marginal role in the conflict resolution and reconciliation efforts. The general exclusion of women from decision-making positions prior to, during and following conflicts reinforces their victimisation. Empowering women in conflict situations would help prevent gender-based violence such as the terrible crimes of rape, forced pregnancy, sexual slavery and others (Naraghi-Anderlini 2006).

It is increasingly recognised that conflict affects men and women differently. It has a wide range of economical, social, and psychological effects which are influenced by gender (Byrne 1996). However, it is also recognised that women are not solely victims of conflict, but that there are times when they gain from conflict, particularly from conflicts related to cattle raiding in the pastoral areas (Byrne 1996). Their gain could be in terms of livestock and/ or social prestige. The livestock gain contributes to food supply and becomes a long-term asset for the family. Being a mother of a brave fighter, a woman will have high social status and prestige. While the whole community suffers from conflict, conflict has its greatest economic, social and psychological impact on women (Byrne 1996).

\subsubsection{Economic impact}

Conflict has its own economic impact particularly on women. Loss of livestock through raids, for instance, has a significant economic impact on pastoral households (Devereux 2006). A case in point was the loss of five 


\section{Women in conflict and indigenous conflict resolution in Eastern Ethiopia}

camels on one day and three cows on another by a Gurgura community. This practice is a continuing process that results in some form of retaliation. Cattle raiding affects the milk supply for which women are responsible. Fear of raids and conflicts also restricts pastoral movements to less fertile areas, which has an impact on stock productivity. This fear of insecurity has a negative impact on the whole community's development efforts, especially with regard to basic services like schools, health facilities and water resource development. Trade (in chat, milk, eggs, and other petty trade) is largely carried out by women in these areas. A 35 year old woman in Erer who has been engaged in chat trading for more than 15 years was a victim of theft. She has eight families who are totally dependent on this trading. Currently, as the conflict is in process, she has no alternative to continuing with the trading. Some women in Gurgura are also engaged in making and selling charcoal as a useful income supplement, but because of insecurities their movements are restricted. Moreover, widows will have a high economic burden when they have lost their partners, as well as the socio-psychological impact. When there is insecurity, women lose their trade opportunities.

\subsubsection{Social and psychological impact}

As women do not participate and are not directly involved in conflicts related to raiding, they are not armed and are not able to defend themselves when they are attacked by their enemies. They suffer more in terms of death and injury than other community members. Women also lose their husbands, sons or other family members due to conflict. Loss of a husband usually means that the woman either has to leave the pastoral sector or be inherited by her husband's brother or close relatives. Inherited wives are often of lower social status than full wives.

Women are usually vulnerable to abduction and rape in times of conflict. For instance, one group of informants said that in the current conflict between the Nolle Oromos and the Gurgura and Issa clans of Somali, those women who are engaged in chat trading are exposed to theft as well as rape. Because of security problems, women's movements are restricted, and that has both economic and social consequences on their lives. Their limited movement 


\section{Bamlaku Tadesse}

because of insecurity limits their ability to maintain their social relationships within their community and their neighbouring ethnic groups. Due to the large scale of intermarriage between Gurguras and Oromos women have relatives living in these communities; but women also form relationships when they trade with neighbouring ethnic groups.

\subsection{The role of women in promoting conflict or in stabilising and searching for peace}

Women play double roles before, during and after conflicts. They have special skills in instigating conflicts as well as in stabilising and searching for peace (Community-based Animal health and Participatory Epidemiology Unit 2003).

\subsubsection{Before conflict}

Women praise victory and success as fruits of peace in order to promote peace and stability instead of enmity. Their ideological propaganda in the community to prevent conflict is important. The key informants outlined some of the traditional phrases that women are accustomed to use when conflict threatens to erupt:

Gobonimo waa adiqo nabad kuseexda (If you sleep in peace, it is your victory and success.)

Nabad haday' jirin hurdo majirto (If there is no peace, you can't sleep well.)

Although women are not allowed to sit and participate in conflict resolution formally, they have the invisible hands that play their role behind the scene. They condemn conflict with their proverbs, like these:

Guul lagama gaaro daqaal sokeeye (Conflict never ends and there isn't success and prosperity through it.)

Nabad waxaad ku wayday daqaal kuma helaysid (You can't achieve your goal through conflict instead of peace.)

Dagaal dad umbao ku baaba'ee dad kuma dhashaan (In conflict people perish but do not reproduce/are not perpetuated.) 


\section{Women in conflict and indigenous conflict resolution in Eastern Ethiopia}

Dhufayskaaga adoon xaga iyo xagaba dayin ku adkayso ilaa intaad ka dhiman (Don't wander here and there and rush to conflict since it destroys you.)

Besides, women also play an important role in child rearing and instructing peace (Ntahobari and Ndayiziga 2003:18). The family and especially women are the primary agents of socialisation. Women educate their children about the norms, principles, sanctions, beliefs and values of their society. Children spend much of their time with their mothers so that they learn a lot from them. Mothers instruct and bless their children in the following ways:

Cadogwgagu kugu maashodo (I wish you not to be killed by your enemy.) Waxaan kuurajayn hayaa inaad ka nabad gasho cudurado khatartaah (I wish you to be free from dangerous diseases.)

Ilaa hay nabad hana siiyo (God gives us peace.)

Wada jir isu difaaca (Defend yourself cooperatively.)

Waa in oadisgarab joogtiin, hakala yaacina isku tiirsonaada (Be united, don't do any thing alone.)

Hadaad kalatagtiin cadawga ayaa idinka quulasanoya (If you aren't united, you will be easily defeated.)

Garab iyo gaashaanba waa midkaliya (Be united and act together.)

\subsubsection{During conflict}

Women are accused of using various ways of instigating men to go to war. They praise men who join the war without hesitation and at the same time they also ridicule, nag and abuse those who are reluctant to join the war. They bless conflicts and prepare food beforehand, and welcome those who return with blessings, songs and dances. During conflicts they have the power to initiate and give moral support to their husbands, fathers, sons and brothers. Songs are sung, particularly by young women, to give courage to the men. There is a Somali saying about the role of women in times of conflict: 'An army with women cannot be easily defeated' (Mohamed 2003:85). There are 


\section{Bamlaku Tadesse}

proverbs and sayings commonly used by Somali women to instigate conflicts at different stages:

Malihin walaalo nooga aar guda cadawgii dilay wiilashayada (We don't have brothers to revenge our enemies who killed our sons.)

Rogu waxay noo dhiibaan goryohooda, ayaguna shqadayada ayay qabraansida lisida lo'ada (Men, give your guns to us and do our jobs like milking cows and others.)

Walaalo malaha miya kuwaay dileen cadaw gayagu? Ragaw miyaydaan iska celin karaynin cadawgiina! (Do those who were killed by our enemies have no brothers? You men can't defend your enemies!)

On the other hand, women play important roles in stabilising situations and searching for peace, since they are victims of conflicts (Conaway and Sen 2005). A better understanding of the role of women in the search for peace in Somali begins with a clear understanding of their status and role in their society. In a polygamous marriage, the first wife is the chief mediator of conflicts in the family. She is responsible for restoring peace and tranquility in situations of conflict between the husband and one of his wives, or among the latter. She also ensures that perfect harmony exists between the young brothers-in-law and their wives. Women are also able to persuade their husbands, sons, brothers and fathers to stop fighting and settle their cases through negotiation. Women have special skills and power in settling conflicts. There are common proverbs and sayings of Somali women about this:

Dagaal wiilbaa $k u$ dhinte ee wilbaa $k u$ dhinta (Males will die and not be born on the battle field.)

Furthermore, women constitute a symbol of peace and cooperation. First, a woman promotes understanding between herself and her husband. Second, she bonds her family and her husband's family. And third, she builds a bridge between her clan/community and that of her husband. When building a healthy society, the first unit and building block is the family. In the process of conflict resolution there is the practice of blood money as compensation. When two clans fight and there is death, steps are taken to organise the 


\section{Women in conflict and indigenous conflict resolution in Eastern Ethiopia}

collection and payment of blood money. A marriage (or marriages) involving the two parties immediately follows this (Mohamed 2003:75-110). This kind of marriage occurs between a man who lost a brother or close relative and a girl from the opposite side. This means a beautiful girl will be selected and given to their rivals as a gift in the form of marriage. The main objective of the marriage is to heal the wounds and to cement the agreement/settlement reached by the two parties. She will give birth to that family in particular and the clan in general as a compensation for the dead person. 'In the Somali culture where there is bloodshed, it must be soaked with birth fluids. The point is the married woman will give birth to sons who will fill the void created by the man who perished in the battle' (Mohamed 2003:103). In their opinion the fluid that comes out first during her delivery can end and cement the bloodshed between the two rival groups forever. This implies that girls play roles for the sustainability of peacebuilding and conflict resolution systems. That is why the married woman is sometimes called godob-reeb which means wound-healer. She assumes this role in conflict situations, particularly when someone is killed. In addition, the marriage is designed to bond the two groups, and thus to minimise the possibility of the erupting of another conflict.

\subsubsection{After conflict}

Women also practice the heerin tradition, which means unmarried women visit the enemy clan without the permission of their parents. The enemy clan welcomes and will arrange a marriage with them. This enables the two distant and enemy clans to bring together and build sustainable peace and stability. The Somali women have always been the centre for integration through marriage that brought together and cemented two different and distant clans (Elster 1989). A Somali proverb emphasises their unique role: 'Only a woman can bring two separate clans together'. When two clans are connecting through marriage, it is the married woman who forms the backbone of the newly established community. She becomes an ambassador of her clan. Somalis say: 'A married woman is an ambassador'. They also say: 'A married woman is a leader'. The bridge she builds between the two 


\section{Bamlaku Tadesse}

communities is one that brings about unity and cooperation (Mohamed 2003:101).

\subsection{Marriage practices and its contribution to social capital formation}

Colson (1953:199-212), Gluckman (1959) and Divale (1976 cited in Ferguson 1984) explored conflict and warfare in relation to the social structure, with particular reference to patterns of decent, marriage, and post-marital residence rules. The essence of their argument is that war is a cooperative male activity. Increased loyalties of men to different social institutions within their society may reduce the possibility that men will use force to resolve conflicts (Ferguson 1984). In other words, relationships established as a result of intermarriage and social integration restrict people from using violent means of resolving differences. Marriage is one way of bonding two rival groups in the process of peacebuilding and conflict resolution. Through marriage, kinship relationships can be established between clans as well as ethnic groups (Pretty and Ward 2001). Thus, women are the primary agents in the process of building social capital. Social capital is the feature of social organisations (such as social networks, interactions, norms, trust, and reciprocity) that facilitate coordination and cooperation and that enable people to act collectively for mutual benefits (Putnam 1993). However, social capital mechanisms have some limits, and are not always effective in resolving some types of conflicts. For such conflicts, people rely on formal mechanisms for arbitration and adjudication (Sanginga et al. 2007).

In the Gurgura tradition, marriage within the clan was not allowed. For example, someone who is a member of the Galwaq (a Gurgura sub-clan) was not allowed to marry a Galwaq partner. These marriage practices between clans and most importantly with their neighbouring Oromos strengthened their bonds and helped them to live together peacefully. The Gurgura men usually married Oromo girls. As a result the Gurgura are a mixture of the two ethnic groups, Somali and Oromo. They speak both the Somali and Afan Oromo languages. Nowadays, this marriage system has gradually changed into a new type of marriage practice, i.e. intra-clan marriage. This happens due 


\section{Women in conflict and indigenous conflict resolution in Eastern Ethiopia}

to the eruption of conflicts between the two ethnic groups. The informants added that it is also the strategy to avoid the loneliness of their girls who will marry outside of their communities. This is because their residence rule after marriage is patrilocal. They believed that marriage outside of their clan and even in distant places is respected and well considered, which is not the case with marriage within the clan. In the previous times unlike today, there was a bride price/wealth in cattle or in kind. According to the key informants, the previous types of marriage were honoured and respected - unlike the recent ones. The recent marriage practice limits the bonding attained within people's kinship relationships. The decrease in kinship relationship between the different clans or ethnic groups may lead to the eruption of hostilities. That is why the current conflict between the Nolle Oromos and the Gurguras as well as the Issas has erupted.

As a marriage alliance can strengthen friendship, it can also instigate conflict if someone marries the fiancée of another. Such a kind of conflict will be resolved on the basis of the traditional conflict resolution mechanism: that the man who marries the fiancée of another should pay a compensation of 15 camels for the loser. Conflict will also erupt when a girl refuses to marry someone after her parents have already decided on and arranged such a marriage. Based on their system of conflict resolution her parents will either return all the expenses including the dowries or substitute her younger sister as his wife. In Somali culture intense and bloody conflicts will erupt when marriage plans are disrupted. Some of the factors that lead to intense conflicts are the following. First, if there is a murder of a woman. Second, if the wife of an individual is raped or if there is any other kind of rape. This is because rape in Somali culture is strictly forbidden. If someone violates the deeply embedded norms and traditions of the culture, he will be punished. Third, if an engaged or married woman is forced into a new marriage, and fourth, if there is verbal abuse or insulting of women (Interview with Qanteras community elders, Erer district, 10 Dec 2008). 


\section{Bamlaku Tadesse}

\subsection{Social institutions}

According to the theory of structural functionalists, social institutions are functionally integrated to form a stable system, and a change in one institution will precipitate a change in other institutions. Societies are seen as coherent, bounded and fundamentally relational constructs that function like organisms, with their various parts (social institutions) working together to maintain and reproduce them. The various parts of society are assumed to work in an unconscious and automatic fashion towards the maintenance of the overall social equilibrium (Etzioni 1995). The Somali societies are therefore structured in a system of clans and sub-clans that bind them together. The Issa as well as the Gurgura communities are traditionally organised through their indigenous method of social organisation and cohesion. There are hierarchical structures in their system of social organisations. At the top, the community is headed by the $\mathrm{Ugaz}^{3}$ who is considered as king of the Issa. The same applies for the Gurgura community. Next, there is the council of elders named the Damina (representatives for each clan), the ordinary pastoralists and lastly the Tumella (artisans in iron working) and Midgan (spearmen who were hunters). The Ugaz has ultimate power over all aspects. He is considered as the peacemaker and mediator between the society and their 'God'. If there is problem like drought, disease or famine, he appeals to his God and comes with a solution. He is considered as having special skill and power endowed to him at birth. If there are conflicts between clans or ethnic groups, he is the one to mediate and negotiate with the rival clan. No one can open an attack on him on his journey to the opposite clan. The council of elders is working in close contact for the smooth functioning of the Ugaz's administration. The clan representatives (clan leaders) act as agents of the Ugaz in their locality.

Furthermore, the clan system forms the basis for most of the core social institutions, norms, sanctions and principles of the society, including

3 Ugaz is considered as king of each of these communities. It is used as a title equivalent to a king and also the administrative or governance system of Issa and Gurgura clans of Somali ethnic groups. 


\section{Women in conflict and indigenous conflict resolution in Eastern Ethiopia}

personal identity, rights of access to local resources, customary law (xeer ${ }^{4}$, blood payment groups, and social support systems (Shivakumar 2003). Both the Tumella and the Midgan are social outcasts and inferior members of the communities. They intermarry with each other and not with the other clans. They are the minorities in Somali society. When there is inter-clan conflict, the mediator who acts as a third party is the one that has no kinship relation (through marriage or blood) with the disputing parties. Even if both the Tumella and the Midgan are not allowed to be elected as elders for conflict resolution, they used to stand between the disputant parties to stop their fighting and deal with their cases through negotiation. In this case, they act as mediators for an immediate cease-fire between the disputants.

In addition, an indigenous social support mechanism in the Gurgura area is named by the title Boku (the village leader), who is responsible for organising and collecting of compensation payments (i.e. blood money/cattle from the clan members). The Boku is accountable immediately to the Damina who is the representative/clan leader. Each sub-clan has their own Daminas. The Damina in turn is accountable to the Ugaz. He receives orders from the Ugaz and acts accordingly. All of them play great roles in the systems of indigenous social support mechanisms. However, all the positions including the kingship (Ugaz) are only held by men. Women by no means have any position in these formal structures of social institutions so that their issues and concerns may not be well addressed.

\subsection{Social gatherings and ceremonies}

Formalities observed on ceremonial occasions are regarded as etiquettes and are formulated in a code of manners describing how one should move about, behave and act in any particular situation. Different scholars are arguing about the ability of dispute settlement mechanisms in restoring harmony in the community. Gluckman (1965) stated that judges were primarily interested in establishing reconciliation between contenders by creating an

4 Xeer is the Somali customary law that encompasses the rules, regulations, principles and sanctions of the various social, political, cultural and economic aspects to which communities strictly adhere. 


\section{Bamlaku Tadesse}

opportunity for friendship rather than bringing the guilty party to justice or reaching some other outcome. There are ritual practices and ceremonies observed by the community, especially when there are abbar (drought conditions), war catastrophes, epidemic diseases, or other natural or manmade calamities in their environs. For such cases they have gatherings near rivers. From different areas, they assemble at a place called mewula (a place where water and shade are available and where it looks green) to appeal to their God. In this ceremony they pray to and beg their God by slaughtering cattle and chewing chat (a stimulating leaf). In these social gatherings the disputants forgive each other and unite as one. According to Turner (1969), rituals are aimed at maintaining social homogeneity or what he termed as 'communitas'. When ruptured social relationships are repaired, it creates a sense of oneness among the disputants. They have only one agenda, which is to communicate with their God. Each and every sub-clan of Issa will bring a different type and amount of items for such a ceremony at a mewula (like cattle, camels, goats, sheep, butter, milk, chat, etc). Women and children are not allowed to participate. However, if the mewula is near their village, they do have their own ceremony at a distance from that of the men. Only those women who have problems such as sickness or infertility are allowed to participate in order to have a blessing from the elders and get solutions for their problems. In this ceremony, if there are disputing parties or groups, they should forgive each other because forgiveness offered in a large crowd of people has the blessing of the elders. This procedure of organising the community in a wider context is termed as $d i q o^{5}$ for the common goal. At the end of the ceremony, they will decide the date and place of their next social gathering.

What women contribute to such social gatherings and ritual ceremonies which are celebrated once or twice a year is the extensions of their domestic work. The Somalis have a culture of ritual ceremonies which strengthen their

5 Diqo means organising a ceremony or ritual practice in a wider context if there are disputing parties or groups in a community. It has its own advantages in maintaining and strengthening their unity and identity as long as they remain committed. 


\section{Women in conflict and indigenous conflict resolution in Eastern Ethiopia}

social unity and identity. For instance, siyaro is observed one or two times a year by all members of the community/clan if there is drought, famine, war or other natural or man-made catastrophes in their locality. It is also celebrated in times of peace for happiness and prosperity. The cost of siyaro is covered by all community members and some of the well-to-do clan members may contribute extra money or gifts in kind like sheep and goats. Another similar ceremony is that of aleberi which is smaller in size than that of siyaro. Its procedure is the same, but its cost is covered by an individual or family member who faces problems like sickness or infertility. The family members invite their neighbours to bless the sick person and pray to their God in mass. Males and females celebrate these ceremonies in different places. In the Somali culture, men and women are not allowed to sit together and/or chat to each other.

Among the Somali, indigenous conflict resolution is mostly practised during the rainy season (Osamba 2001). This is because of the fact that those animals (cattle, camels, and others) that are collected from clan members for compensation must be well fed and fat rather than thin. This happens when the pasture land becomes green. The resolution practices and ceremonies mostly take place near river basins. If the conflict occurs during the dry season, the resolution proceedings will be postponed for half a year or up to two years until the rainy season is coming. If there is murder during a conflict, compensation (blood money) will follow. The council of elders will have their own share of animals (in principle it is about 25) from the total amount of compensation contributed by the clan members. This share will be used for running the resolution process. Some of these animals will be slaughtered on the spot for the ceremony. Besides this, the murderer will bring a sheep and slaughter it. Its meat will not be eaten by them but rather given to wild animals as sedeqa $a^{6}$ for the soul of the deceased. This happens at the end of the whole ceremony. The ceremony will take place near the village of the clan who is going to pay the compensation. All clan members should

6 Sedeqa is a practice of feeding the needy (humans and animals) in several situations, according to Somali culture. This has probably been derived from Muslim culture. 


\section{Bamlaku Tadesse}

contribute for the collection of animals for the compensation. Its procedure is that 15 cattle/camels will be handed over via the elders during the first stage of compensation transfers. Then, those who pay the compensation will ask the elders to give them time until the next rain is coming so that all clan members will be back at their homesteads, which will enable them to contribute animals for the compensation. With this procedure of elapsed time all of the decided compensations will eventually be transferred. Compensation may not have to be implemented fully if the offender shows his willingness and actually starts to pay.

The Ugaz has his own enforcing mechanisms or sanctions in the process of conflict resolution and payment of compensation. First, the Ugaz will ask the Damina (representative of Ugaz, for each sub-clan) of the culprit. The Ugaz then punishes the offender twice: for his initial mistake and for his refusal of the elders' decision. His refusal is considered as an insult to the remaining sub-clan members. Second, there is a social control mechanism of social exclusion. Social control is the way in which the entire social order coheres and maintains itself, operating as a whole in a changing equilibrium. The informal means of social control mechanisms (beliefs, customs, folkways, mores, etc) are important here. For defiant cases there will be social exclusion. This means, the man will be socially excluded from all social activities. For example, someone may not get support from the community if he has a problem (like losing his cattle for a variety of reasons). This means that there is no social guarantee/insurance if someone is totally excluded by his clan members.

\subsection{Judicial procedures in dealing with disputes}

For an intra/inter-clan conflict case the judges (gudis, sometimes called

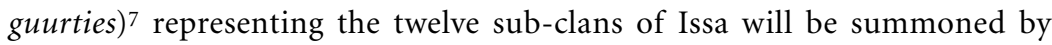
the Ugaz. The gudis have a secretary (qore) who is chosen from the twelve judges as the one with the best skill of memorising and recording all the cases of the disputants orally. First the plaintiff (dewoye) will narrate his case

7 Gudis or guurties are traditional legislators representing the 12 sub-clans of Issa. They are considered as judges as well as law makers in the Issa community. 


\section{Women in conflict and indigenous conflict resolution in Eastern Ethiopia}

in front of the judges. Then the defendant (ledewoye) will respond to the charge against him. The two parties will also be ordered to present their cases for the second time in front of the judges. The judges listen to them carefully to determine whether there are differences between their first and second presentations. If there are different ideas or points in their presentations, the qore will cross-check their cases one by one. The judges will then listen to three witnesses (merkatee). The merkatee will be examined and challenged by the judges, and especially by the qore, in order to identify the truth. After a thorough examination of both presentations, the judges will finalise their decision. The accused will deliver the compensation decided upon in front of the judges within three to four days. Audiences are allowed to participate in this procedure.

The judges (gudis) also have the responsibility to settle dispute cases related to injuries to some parts of the human body. According to the Issa customary law, the injured one should first slaughter a sheep 'to heal the wound'. This is to check whether he is really injured or not. It is assumed that for false cases he may not slaughter his sheep. Then the offender should pay a compensation of one sheep for the injured. This is repeated from time to time (approximately every two months) until the injury is completely cured. The judges then check whether this is indeed the case. They request him to tell them the truth and take the compensation. If he takes an oath falsely, it is believed that what he eats and drinks will hurt him as if it was poisoned. If the injured one is not yet married, he will not marry until the judge checks the wound and gives his approval. He will not be recruited as a soldier in his clan or participate in cattle raiding. This is because of the fear that if he were to die in these combats, it will be linked to the first injury and his clan may ask boqole (blood money). On the other hand, if the judges checked and approved him, his clan may not ask boqole if he dies in such combats. An individual who is not satisfied by the elders' decision has the right to appeal to another court. Almost every individual of the Issa community is accustomed to the Issa customary law so that the judges can take no chances of passing unfair decisions through corruption. 


\section{Bamlaku Tadesse}

There is the Ergeda tradition of choosing and sending a group of people as a peace envoy to the rival clan/group for negotiation towards a peace agreement. Its basic mission is to promote and strengthen societal stability and cohesion. The Somalis are careful as to whom they would choose as a peace envoy. The would-be Ergeda members are required to possess a wide range of qualities and competencies, including a sense of responsibility, patience, good personality, oratory abilities and decency. The well-known and experienced community elders who never lie or cheat others and are therefore trusted by their community, will be chosen as peace envoys. They are expected to be well-versed in customary law and are required to know exactly what the problem is and what is at stake. They are a select group of individuals with rare qualities. That is why the Somali customary law urges people not to harass or harm the peace emissaries. The Ergeda can be dispatched by one of the warring parties or by a neutral community/clan like that of the Midgan and Tumella (Mohamed 2003:103).

\section{Case study on conflict resolution}

There was a conflict between two individuals on the issue of the possession of a baby camel. This conflict happened after the two camels gave birth on the same day and at the same place. During the night a hyena came and ate the baby of one of the camels. The next day the two mother camels were standing and looking after the remaining one. When the owners of the two camels came and saw what had happened, each of them claimed the kid which was alive. This created conflict between the two. Both men then appealed to the modern court to resolve their conflict. The court asked them whether they had eye witnesses or not. They replied that they had no eye witnesses since the kid disappeared during the night time. The court was challenged and unable to solve their problem, so it then referred the matter to the elders' court for traditional resolution. The elders asked to have time until the dry rivers become full. Traditionally conflicts are mostly resolved during the rainy season near rivers when animals have become relatively fat. Based on their request, the resolution was postponed to the rainy season. The elders' court went to the nearby river and started their judicial procedures. They ordered a man to carry the kid camel and cross the river. While the kid was crying as it was taken from its mother, the camel which was 


\section{Women in conflict and indigenous conflict resolution in Eastern Ethiopia}

the mother immediately tried to jump into the river in order to save the life of its baby. The second camel which was not the mother stayed on the bank of the river. The elders' court then identified the baby camel as belonging to the one that tried to get into the river. They sent their method of resolution as well as their decision to the modern court. The modern court admired their method of resolution and accepted their decision. From that time onwards, said the community elders, the modern court used this method for similar cases. (Interview at Fetulle Kebele, Erer district, 17 September 2008)

\subsection{Compensation}

There is the tradition of blood money as compensation for different kinds of offenses. The type and amount of compensation are different for different conflict cases. It is stated in the Ugaz's constitution that for killing a man it will be 100 camels and for killing a woman 50 camels. This is unequal treatment but the tradition is still accepted in this way. In each case, fifteen camels are given to the family of the deceased while the rest are distributed to the clan members according to the share they contributed during the collection of blood money. It is considered as their insurance. If a girl is raped by someone from another clan, intense conflict will follow between the clans. In such a case, the compensation is 450 birr in cash or 15 cattle in kind. If some part of the human body is broken during conflict, the compensation is clearly defined. For instance, for each left part of the human body, the compensation is 16 fertile female camels and for the right part it is 15 fertile female camels. The total amount of compensation for all parts of the human body is equal to 100 camels. It is assumed that the left part of the human body is the most important part, since the left hand and shoulder are strong and carry heavy loads like the shield or gun. Compensation for killing animals is also clearly stated in the Ugaz's constitution. For example, 12 and 6 fertile female sheep for a camel and a cow respectively and one goat for a dog. For each kind of conflict and its resolution, methods, rules and principles of compensation are clearly outlined in the Ugaz constitution.

When a conflict has to be resolved, the Ugaz of Gurgura will call the eight sub-clans. One of the members of the Sanchille sub-clan will put a crown 


\section{Bamlaku Tadesse}

named imameta on the head of the Ugaz. In this assembly, women are not allowed to participate formally for cultural reasons. The amount and type of compensation in the Gurgura society differ according to the nature of the incident. If it was not deliberate, and therefore not intensely violent, the compensation will only be partial.

The following are some examples of compensation in cases of rape, according to an interview with Fetulle community elders, Erer district, 30 0ctober 2008:

- Uncircumcised young girl: 15 camels $^{8}$

- A mature girl not yet engaged: 5 camels (less than in the case of a young girl, because of her maturity)

- Someone's fiancée: 15 camels (the compensation being given to her fiancé, who will then marry her sister)

- A woman carrying her male baby on her back: 18 camels (on the assumption that the boy was also raped)

- Widow within her mourning period (4 months and 10 days): 15 camels

- An old woman who uses a stick for walking: 16 camels

In the same interview, a special case of compensation was also explained. If someone is murdered during an inter/intra-clan conflict, an immediate compensation during the burial ceremony can lead to a cease-fire and avoid revenge. Such compensation comes in the form of a camel, which is then slaughtered before the deceased is buried. An amount of 1000 birr is added to cover the expenses of the burial ceremony, and the murder weapon is handed over to the close relatives of the deceased.

\section{Conclusion and Recommendations}

\subsection{Conclusion}

The paper has examined the system of indigenous conflict resolution mechanisms among the Issa and Gurgura communities of Somali. Women

8 When these compensations were determined by the elders, a camel was rated at 30 birr for payments in cash, but this is no longer a realistic value. 


\section{Women in conflict and indigenous conflict resolution in Eastern Ethiopia}

play double roles in times of conflicts, i.e. they have skills of promoting conflict as well as of stabilising situations and searching for peace. They play roles in the formation of social capital through marriage and kinship relations. Women have always been the centre for integration - through marriages that brought together and cemented two different and distant clans. They play vital roles for the sustainability of peacebuilding and conflict resolution.

However, their role in stabilising conflict situations and searching for peace is always an informal one. Due to the patriarchal nature of the Issa and Gurgura communities, women are not allowed to participate in formal conflict resolution mechanisms. They are not present during deliberations even if they are the majority of the victims of the conflict. They are represented by men in all the important public decision-making events. As a result, their issues are not well addressed. The blood-price of a woman is less by half than that of a man. She is not allowed to pay or receive compensation. It is rather the clan of her father or husband that will take over on her behalf. Therefore, in order to have a fair system of conflict resolution mechanisms, there should be the representation of all sections of the society that are involved in one way or another in an ongoing conflict. This needs a fundamental shift in the cultural forms that sanction gender-discriminating actions, as in the patriarchally organised Issa and Gurgura communities.

\subsection{Recommendations}

- In line with conflict theory, where there is scarcity of resources there is always competition which leads to conflicts. That means poverty is a major cause of conflict. Women are, therefore, the primary victims of poverty and conflict. The inclusion of gender perspectives into conflict analyses can be beneficial not only to ensure better understanding of conflict dynamics, but also to highlight the linkages with development and poverty issues (Naraghi-Anderlini 2006).

- In order to enhance women's participation in peacebuilding and conflict resolution, there should be a focus on the eradication of poverty. In order to encourage women to participate fully in decision-making events, different 


\section{Bamlaku Tadesse}

programs like the training of women in income-generating activities and micro-credit undertakings should be designed and implemented.

- According to the community elders, the position of the Ugaz is currently not held by any one and is not fully functional. Due to the influence of modernisation, younger generations are not willing to accept it as an institution. They consider it as backward and primitive. Therefore, there should be the revitalisation and appreciation of the indigenous community institutions like the Ugaz which is responsible for all aspects of societal problems like conflict resolution. This could be possible through institutional socialisation of the younger generations within their indigenous cultures. Such socialisation should include the preservation of positive moral and cultural values, and the identifying of elderly resource persons who have ample experience in their traditional customary law so as to document and transfer it to the next generation.

\section{Sources}

Ahmed, S. 2005. Conflict is everyday business. Changing nature of local conflict in federal Ethiopia: The case study of Ma'eso district. Unpublished synthesis paper.

Bates, Prue A. 2000. Women and peacemaking. Australian National University Development Bulletin 53. Canberra, Australian National University.

Burton, John and Frank Dukes eds. 1990. Conflict readings in management and resolution. New York, St. Martin's.

Byrne, Bridget 1996. Gender, Conflict and Development. Volume I Overview BRIDGE Report No. 34. December 1995, revised July 1996. Brighton, Institute of Development Studies, University of Sussex.

Colson, Elizabeth 1953. Social control and vengeance in Plateau Tonga society. Africa Journal, 23, pp. 199-212.

Community-based Animal health and Participatory Epidemiology Unit (CAPE) 2003. Conflict and pastoralism: Pastoral women as peacemakers. Addis Ababa, Institutional and Policy Support Team, African Union.

Conaway, Camille and Anjalina Sen 2005. Beyond conflict prevention: How women prevent violence and build sustainable peace. New York, Global Action to Prevent War; Geneva, Women's International League for Peace and Freedom.

Devereux, Stephen 2006. Vulnerable livelihoods in Somali region, Ethiopia. Institute of Development Studies. University of Sussex, Brighton, UK. 
Elster, Jon 1989. The cement of society: A study of social order. Cambridge, Cambridge University Press.

Etzioni, Amitai 1995. The spirit of community: Rights, responsibilities and the communitarian agenda. London, Fontana Press.

Ferguson, R. Brian ed. 1984. Warfare, culture and environment. New York, Academic Press.

Gluckman, Max 1959. Custom and conflict in Africa. Oxford, Basil Blackwell.

Gluckman, Max 1965. The ideas in Barotse jurisprudence. New Haven, Yale University Press.

Hodgson, Geoffrey M. 2006. What are institutions? Journal of Economic Issues, XL (1).

Kandagor, Daniel K.2005. Rethinking pastoralism and African development: A case study of the Horn of Africa. Egerton University, Njoro, Kenya.

Manchanda, Rita 1999. Hearing women's voices on conflict: An overview. Paper presented at an international conference on Women and Violent Conflict: Global Perspectives, London, 5-6 May (Excerpts posted to Women and Armed Conflict List by International Alert).

Mohamed, Abdi M. 2003. The role of Somali women in the search for peace. In: UNESCO 2003, pp. 75-110.

Naraghi-Anderlini, Sanam 2006. Mainstreaming gender in conflict analysis: Issues and recommendations. Social Development Papers on Conflict Prevention and Reconstruction, No. 33. New York, The World Bank.

Ntahobari, Josephine and Basilissa Ndayiziga 2003. The role of Burundian women in the peaceful settlement of conflicts. In: UNESCO 2003, pp. 11-26.

Osamba, Joshia 2001. Peace building and transformation from below: Indigenous approaches to conflict resolution and reconciliation among the pastoral societies in the borderlands of Eastern Africa. African Journal on Conflict Resolution, 2 (1), pp. 71-84.

Pastoralist Forum Ethiopia 2006. Narrative Activity and Performance Report, January through December 2005. Addis Ababa, Pastoralist Forum Ethiopia.

Pretty, Jules and Hugh Ward 2001. Social Capital and the Environment. World Development, 29 (2), pp. 209-227.

Putnam, Robert 1993. Making democracy work: Civic traditions in modern Italy. Princeton, Princeton University Press.

Rosenblad, Vilda 2007. Women, peace and security. Geneva, Women's International League for Peace and Freedom.

Sanginga, Pascal C., Rick N. Kamugisha and Andrienne M. Martin 2007. The dynamics of social capital and conflict management in multiple resource regimes: A case study of the southwestern highlands of Uganda. Ecology and Society, 12 (1). Available from: $<$ http://www.ecologyandsociety.org/vol12/iss1/art6/> 


\section{Bamlaku Tadesse}

Shivakumar, Sujai J. 2003. The place of indigenous institutions in constitutional order. New York, Kluwer Academic Publishers.

Somali Region Pastoral and Agro-pastoral Research Institute (SoRPARI) 2007. Annual Report 2006/07. Jijiga, Ethiopia, SoRPARI.

Turner, Victor 1969. The ritual process: Structure and anti-structure. Chicago, Aldine Publishing Company.

UNESCO 2003. Women and peace in Africa: Case studies on traditional conflict resolution practices. Paris, UNESCO. 